OPEN ACCESS

Edited by:

Simone Pacini,

University of Pisa, Italy

Reviewed by:

Christopher V. Carman,

Harvard University, United States

Julie Fradette,

Laval University, Canada

*Correspondence:

Coralie Sengenès

coralie.sengenes@inserm.fr

tThese authors have contributed equally to this work

Specialty section: This article was submitted to Stem Cell Research,

a section of the journal

Frontiers in Cell and Developmental

Biology

Received: 24 August 2020

Accepted: 18 November 2020

Published: 08 January 2021

Citation:

Girousse A, Mathieu M, Sastourné-Arrey Q, Monferran S, Casteilla $L$ and Sengenès $C$ (2021)

Endogenous Mobilization

of Mesenchymal Stromal Cells:

A Pathway for Interorgan

Communication?

Front. Cell Dev. Biol. 8:598520. doi: 10.3389/fcell.2020.598520

\section{Endogenous Mobilization of Mesenchymal Stromal Cells: A Pathway for Interorgan Communication?}

\author{
Amandine Girousse ${ }^{1 \dagger}$, Maxime Mathieu ${ }^{1 \dagger}$, Quentin Sastourné-Arrey ${ }^{2}$, Sylvie Monferran ${ }^{1}$, \\ Louis Casteilla ${ }^{1}$ and Coralie Sengenès ${ }^{1 *}$
}

1 Stromalab, Université de Toulouse, CNRS ERL5311, EFS, INP-ENVT, INSERM U1031, Université Paul Sabatier, Toulouse, France, ${ }^{2}$ Sprott Center for Stem Cell Research, Ottawa Hospital Research Institute, Department of Cellular and Molecular Medicine, University of Ottawa, Ottawa, ON, Canada

To coordinate specialized organs, inter-tissue communication appeared during evolution. Consequently, individual organs communicate their states via a vast interorgan communication network (ICN) made up of peptides, proteins, and metabolites that act between organs to coordinate cellular processes under homeostasis and stress. However, the nature of the interorgan signaling could be even more complex and involve mobilization mechanisms of unconventional cells that are still poorly described. Mesenchymal stem/stromal cells (MSCs) virtually reside in all tissues, though the biggest reservoir discovered so far is adipose tissue where they are named adipose stromal cells (ASCs). MSCs are thought to participate in tissue maintenance and repair since the administration of exogenous MSCs is well known to exert beneficial effects under several pathological conditions. However, the role of endogenous MSCs is barely understood. Though largely debated, the presence of circulating endogenous MSCs has been reported in multiple pathophysiological conditions, but the significance of such cell circulation is not known and therapeutically untapped. In this review, we discuss current knowledge on the circulation of native MSCs, and we highlight recent findings describing MSCs as putative key components of the ICN.

Keywords: adipose tissue, native mesenchymal stromal cell, stroma homeostasis, endogenous reservoir, rare cells in circulation

\section{INTRODUCTION}

Each organ is a combination of a functional compartment, the parenchyma, and a stromal compartment, the stroma, supporting the parenchymal cells of the organ (Feeback, 1987). The main function of the stromal compartment is to structure and remodel functional tissue in order to ensure organ homeostasis (Scadden, 2012). In normal tissue, stroma maintains the tissue microenvironment and sustains cell growth in various ways with spatial and temporal selflimitations (Huet et al., 2019). Conversely, stroma imbalance nurtures organ imbalance, which can eventually lead to tumor progression (Valkenburg et al., 2018). Among the cell types residing in the stroma, mesenchymal stem/stromal cells (MSCs) are key components allowing stroma's supportive function. MSCs attract lots of attention because they hold great promise for a multitude 
of emerging therapies in regenerative medicine since they promote tissue repair in various degenerative contexts such as osteoarthritis, bone defects, myocardial infarction, inflammatory bowel disease, or neurodegenerative disorders. As such, they have been the subject of clinical trials for more than 20 years (Galipeau and Sensébé, 2018; Pittenger et al., 2019). MSC identification and characterization rely on in vitro work, and long steps of culture are needed to collect a usable amount of cells (Dominici et al., 2006). Culture-expanded MSCs consist of a heterogeneous population of cells exhibiting various phenotypes and functional properties, and the extent of these properties depends on the tissue, donor, and species of origin, isolation technique, and culturing protocols (Ankrum et al., 2014). Such variations are known to limit the potential of MSCs for clinical translation, and strategies to enhance engraftment are needed (Hou et al., 2005; Hénon, 2020).

In the past few years, investigating the endogenous repair mechanisms of injured tissues has paved the way for future "in situ" strategies to potentiate the body's own repair capacity (Andreas et al., 2014). In this regard, pharmacological activation of endogenous stem cell mobilization from either the blood or a tissue-specific niche is a promising approach (Krankel et al., 2011). Consequently, both triggering and controlling the endogenous mobilization of MSCs represent an additional strategy to achieve effective tissue repair and regeneration. In this review, we present the current state of knowledge and unresolved gaps about the circulation of endogenous MSCs and propose MSC interorgan trafficking as a complementary pathway of communication.

\section{WHAT DO WE KNOW ABOUT THE CIRCULATION OF ENDOGENOUS MESENCHYMAL STEM/STROMAL CELLS?}

\section{Circulating Mesenchymal Stem/Stromal Cells: Myth or Reality?}

Studies reporting the mobilization, circulation, and recruitment of endogenous MSCs are sparse and heterogeneous (Roufosse et al., 2004) and generated lots of conflicting results (Ojeda-Uribe et al., 1993; Lazarus et al., 1997; Zvaifler et al., 2000; Wexler et al., 2003). Consequently, the presence of blood circulating MSCs is still debated (Mansilla et al., 2006; Wang et al., 2006; Hoogduijn et al., 2014).

Yet, several studies show that endogenous MSCs are found in the bloodstream of various species, but their frequency is rare [0-0.025 colonies $/ 10^{e} 6$ of peripheral blood mononuclear cells (He et al., 2007)]. Conversely, the circulation of endogenous MSCs greatly increases in response to various types of injuries. Indeed, skeletal traumas, regardless of their severity (Alm et al., 2010), cardiomyopathies (Marketou et al., 2014, 2015), coronary syndrome (Wojakowski et al., 2008), skin burns (Mansilla et al., 2006), liver damages (Chen et al., 2010; Liu et al., 2015), and some types of cancers (Fernandez et al., 1997; Bian et al., 2009) are some examples of clinical situations triggering this increase. Whether endogenous MSCs circulate in vivo is not a matter of debate anymore but rather a matter of methods of investigation, time frame (Churchman et al., 2020), and clinical context. Such limitations relate to a lack of precise knowledge of functional, phenotypic, and molecular criteria that define endogenous circulating MSCs.

\section{Immunophenotypic Characteristics of Circulating Endogenous Mesenchymal Stem/Stromal Cells}

Despite extensive efforts to characterize MSCs, the definition of in vivo identity(ies) of MSCs is still very obscure (Parekkadan and Milwid, 2010). In humans, the canonical MSC surface marker combination $\mathrm{CD}_{3} 3^{+} / \mathrm{CD} 44^{+} / \mathrm{CD}_{3} 3^{+} / \mathrm{CD} 90^{+} / \mathrm{CD} 105^{+} / \mathrm{CD} 34^{-} / \mathrm{CD} 31^{-} / \mathrm{CD} 45^{-}$ directly derives from their in vitro culture expansion (Dominici et al., 2006). However, many factors, from the harvesting methodology to the conditions of cell culture, dramatically influence MSC phenotype and functions (Bara et al., 2014; Jones and Schäfer, 2015; Pittenger et al., 2019; Walter et al., 2020). In that regard, we and others have demonstrated that cell surface marker profiles of in vitro expanded human MSCs differ compared to freshly isolated cells and those residing in their native microenvironment (Sengenès et al., 2005; Maumus et al., 2011; Bara et al., 2014). In particular, the absence of CD34 is considered among the prerequisites to identify MSCs; however, we have shown that CD34 is strongly expressed in native adipose-derived MSCs and that cell culture abolishes its expression (Sengenès et al., 2005; Maumus et al., 2011). Moreover, though some of the MSC markers appear constitutively expressed regardless of environment (Jones et al., 2006), “immunophenotypic drifts" are expected while MSCs circulate. Indeed, the expression of membrane markers such as CD29, CD44, CD73, and CD90, which all regulate MSC adhesion/migration processes, is known to change dramatically to allow MSC detachment and further migration (Rege and Hagood, 2006; Ode et al., 2011; Qian et al., 2012; Xu and Li, 2014). Consequently, using flow cytometry analysis with a combination of surface markers (validated in vitro) to detect circulating native MSCs may lead to underestimation and generates conflicting results when compared with studies using functional assays to detect MSCs [such as colony-forming unit-fibroblast (CFU-F) activity] (Fellous et al., 2020; Figure 1). Indeed, the level of blood circulating CD $45^{-} / \mathrm{CD} 271^{+}$MSCs shows higher correlation to CFU-F numbers than the one of $\mathrm{CD}^{-} 5^{-} / \mathrm{CD}^{+} 3^{+} / \mathrm{CD} 0^{+} / \mathrm{CD}_{105^{+}}$MSCs (Rebolj et al., 2018). This illustrates that understanding MSC heterogeneity holds promise for refining the definition of MSCs. In that regard, the analysis of MSC heterogeneity from various tissue [bone marrow (BM), adipose tissue (AT), skeletal muscle] is under active investigation using single-cell RNA sequencing technologies (Burl et al., 2018; Hepler et al., 2018; Baryawno et al., 2019; Wolock et al., 2019). However, though powerful, those studies will inform about the signature(s) of native tissue-resident MSC subpopulations but will fail for circulating MSCs. Interestingly, high-throughput technology capable of efficiently capturing 


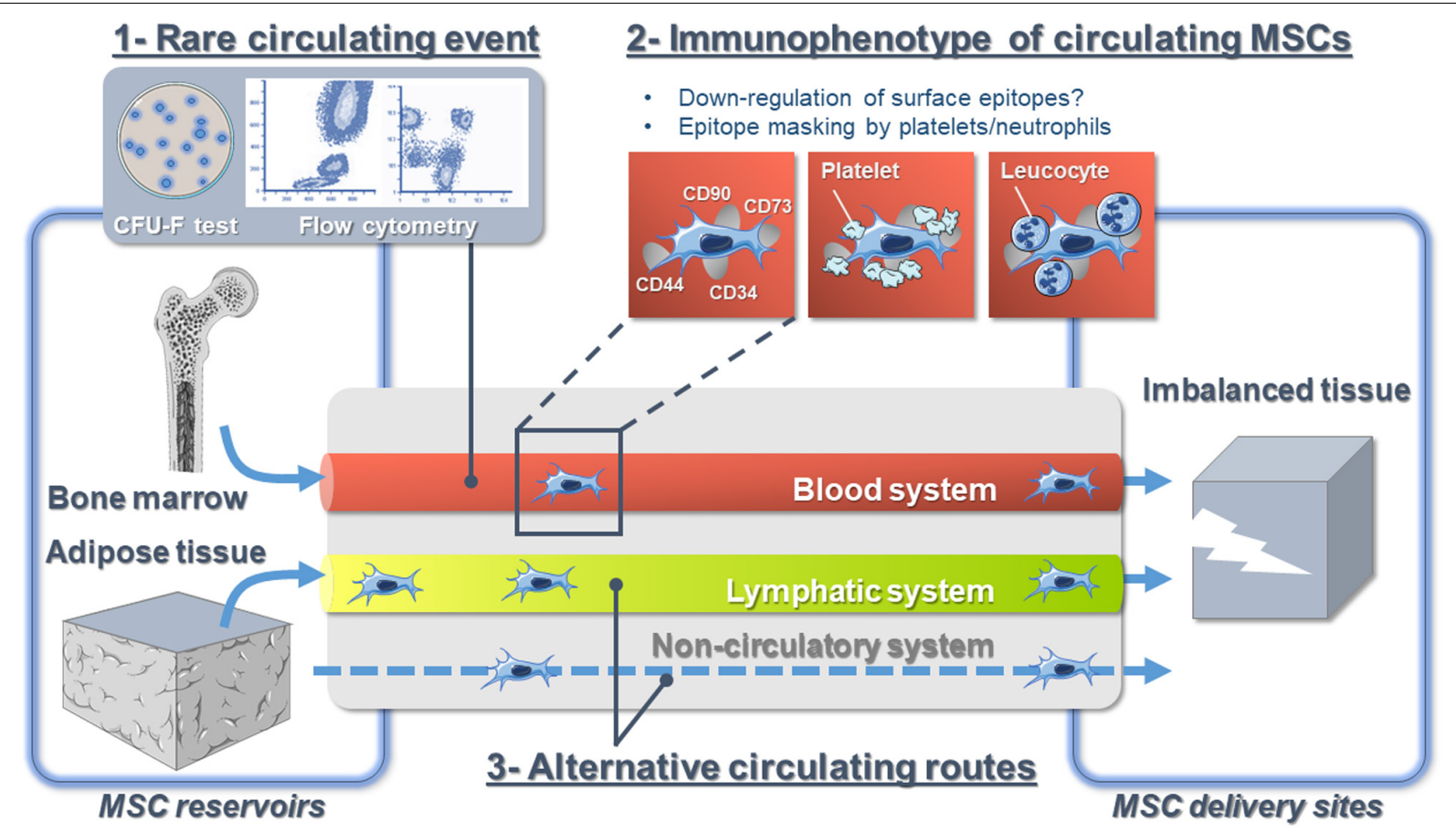

FIGURE 1 | The hypotheses explaining the controversy over endogenous mesenchymal stromal cell circulation in vivo.

without marker-based approach and molecularly interrogating rare cells in the circulation at single-cell resolution is under development to study circulating tumor cells (CTCs) (Cheng et al., 2008). Those technologies will be of great utility both to capture and to enable single-cell transcriptome analysis of rare and limited cell populations of circulating endogenous MSCs.

\section{How Do Endogenous Mesenchymal Stem/Stromal Cells Navigate in the Bloodstream?}

Little is known about the behavior of MSCs in flowing blood, and our current understanding mostly derives from intravascular infused cultured-expanded MSCs from which we could infer the behavior of native MSCs. While circulating MSCs are always considered to be isolated cells floating in the bloodstream, recent studies demonstrated the close interaction of MSCs with the blood microenvironment. Indeed, using in vivo confocal microscopy, it has been reported that the majority of intravascular MSCs are in contact with platelets and/or neutrophils (Teo et al., 2015). Additionally, BM-derived MSCs bind platelets that shield them from surface adhesion, so that they barely adhere at all in the blood flow via a mechanism involving podoplanin, the endogenous ligand for C-type lectin-like receptor 2 (CLEC-2) (Sheriff et al., 2018; Ward et al., 2019). CLEC-2 is being expressed broadly, including in platelets, inflammatory leukocytes, and lymphatic endothelial cells. Moreover, platelet depletion decreases MSC trafficking to sites of injury (Langer et al., 2009; Teo et al., 2015). Platelet functions extend beyond the immediate environment of the thrombus (Golebiewska and Poole, 2015). For instance, they play important roles for tissue regeneration (Eisinger et al., 2018), and they also contribute to tumor metastasis (Tesfamariam, 2016). Indeed, it is admitted that CTCs are partly covered with platelets to provide them with "stealth" properties and help their survival in the circulation, where they are challenged by physical forces in the circulation (Nieswandt et al., 1999; Heeke et al., 2019). Whether circulating endogenous MSCs are not single cells traveling the blood alone but are accompanied by other cell types and partners possibly modifying their immunophenotype needs more investigations (Figure 1). However, targeting the interaction of MSCs with other cells is a promising tool and future research to improve endogenous MSC detection, collection, and trafficking.

\section{What if Not Just the Blood?}

The peripheral blood is considered as the bona fide route for native MSC trafficking (He et al., 2007). Indeed, the detection of blood-borne CFU-Fs was earlier (Maximow, 1928) than the detection of BM CFU-Fs (Friedenstein et al., 1968, 1970). However, it is well established that some types of stem cells such as hematopoietic stem cells recirculate daily between the $\mathrm{BM}$ and the blood and egress to extramedullary tissues via the lymphatic system (Massberg et al., 2007). Until a few years ago, the composition of the lymphatic fluid was virtually unknown. This lack of knowledge was mostly due to the technical difficulty in cannulating lymphatic vessels and the small amount of collected fluid. Over time, some of these technical issues have been resolved, and as such, lymph "omic" composition in physiological and pathological conditions received a lot of 
attention (Santambrogio, 2018). However, the precise cellular composition of lymph is still obscure, and immune cell transit was mostly investigated (Platt and Randolph, 2013). Yet, we have demonstrated that MSCs originating from AT, the ASCs (Zuk et al., 2001; Gimble and Guilak, 2003), are found in the lymph fluid in response to lymph node inflammation (Gil-Ortega et al., 2013). Other studies indicate that systemically infused MSCs can be found in secondary lymphoid organs [e.g., mesenteric lymph nodes after intracardiac infusion (Li et al., 2012), lymph nodes, Peyer patches, spleen (Schwarz et al., 2014)]. Interestingly, Han et al. (2020) very recently reported the presence of lots of circulating cells able to form spheroids in the thoracic duct of a mouse model of melanoma, though distant metastases were not developed. Altogether, those data suggest that as cancer cells do, MSCs may exploit several bodily fluid systems as natural transportation routes (Follain et al., 2020; Figure 1).

Whether the clinical context, fluid biomechanics, and tissue microenvironment have a role in the initial choice of the fluid route is unknown. As well, accessibility of blood and lymphatic vasculature may strongly influence the pathway taken for MSCs to transit. Finally, flow velocities and shear stress are lower in lymphatic vessels (Dixon et al., 2006), and lymphatic dissemination has been suggested as less deleterious than dissemination through the blood for some type of cancer cells (Wong and Hynes, 2006). Lymph fluid could thus represent a more favorable route for MSCs since their survival may benefit from the passive, low-shear system of fluid transport characteristic of lymphatics. Consequently, an improved understanding of this process might provide a new avenue for targeting MSC transit and might explain conflicting results. At last, the fibroblastic nature of MSCs allows considering extra-circulatory alternative routes, such as connective tissues, for MSC mobilization (Figure 1). The potential for such trafficking events, putative mechanisms, and potential functional roles represents important questions for future investigation.

\section{WHICH PHYSIOLOGICAL RESERVOIRS MAY BE MOBILIZED?}

MSCs reside in virtually all postnatal organs and tissues; however, not all organs contain the same amount of MSCs (da Silva Meirelles et al., 2006; Crisan et al., 2009). BM is generally considered as the major reservoir of mobilizable MSCs (Koh et al., 2007; Koning et al., 2013). Nevertheless, together with the absence of unique specific markers, the lack of MSC tissue-specific markers impairs the parallel analysis of various physiological reservoirs. Consequently, it is very likely that the role played by extramedullary organs in participating in the pool of circulating endogenous MSCs is underestimated. Indeed, AT is a large source of MSCs, named ASCs (Zuk et al., 2001; Gimble and Guilak, 2003). The uncultured stroma-vascular fraction (SVF) from AT usually contains up to $30 \%$ of ASCs. This is 2,500-fold more than the frequency found in BM (Fraser et al., 2008; Baer and Geiger, 2012). Consequently, AT represents so far the largest physiological reservoir of MSCs.
In the attempt of investigating to what extent AT contributes to the pool of circulating endogenous MSCs, we and others have shown that endogenous ASCs are mobilizable and that such mobilization is triggered in response to various types of stresses from inflammation to fat overload (Zhang et al., 2009; Kolonin, 2012; Gil-Ortega et al., 2013, 2014; Girousse et al., 2019). Consequently, AT also largely accounts for the pool of circulating endogenous MSCs, but animal models are still needed to clearly evaluate the respective part played by BM vs. AT.

\section{WHY DO ENDOGENOUS MESENCHYMAL STEM/STROMAL CELLS CIRCULATE?}

Whatever the reservoir, circulating endogenous MSCs belong to the group of blood-circulating rare cell populations, classified by Schreier and Triampo (2020) into "constructive" and "destructive" cell types. MSCs are mostly considered as constructive cell types because of their repair and/or homeostasis maintenance properties. The current knowledge on the functional roles of MSCs mainly relies on studies using in vitroexpanded MSCs (Keating, 2012; Galipeau and Sensébé, 2018; Pittenger et al., 2019). The struggles in clearly defining native MSCs negatively influence advancement in understanding their role(s) in vivo and what is more the role of their circulation. Last, since MSCs virtually reside in all postnatal organs and tissues (da Silva Meirelles et al., 2006; Crisan et al., 2009), one may wonder why MSCs circulate toward distant "injured/inflamed" sites, while resident ones could perform the same activities.

\section{The Interorgan Communication Network}

The long-term maintenance of an organism's homeostasis and health relies on the accurate regulation of organ-organ communication (Silverthon et al., 2009). To do so, the central nervous system regulates many organ behaviors using hormones or neurons and organs developed systems to directly communicate their states to one another. This interorgan communication network (ICN) is made up of soluble factors such as peptides, proteins, and metabolites that act between organs to coordinate essential and specialized cellular processes under homeostasis and stress (Droujinine and Perrimon, 2016; Figure 2). Recent studies show that more than $15 \%$ of the protein-coding genome encodes for roughly 3,000 secreted proteins, but only a handful of them has been properly annotated (Uhlen et al., 2010; Lindskog, 2015). Consequently, the nature of the ICN remains largely a mystery (Droujinine and Perrimon, 2013). The interorgan communication is seen to occur through secreted molecules; however, accumulating data show that organs communicate their state via other ways. For instance, extracellular vesicles (EVs) have emerged as a novel messaging system of the organism, mediating cell-cell and interorgan communication (Gould et al., 2003). EVs are secreted membranous structures, entrapping nucleic acids, diverse cellular proteins, and metabolites, and are predicted to transfer their packaged molecules from one cell to another (Gould et al., 2003). EVs traffic to local or distant targets to execute defined biological 


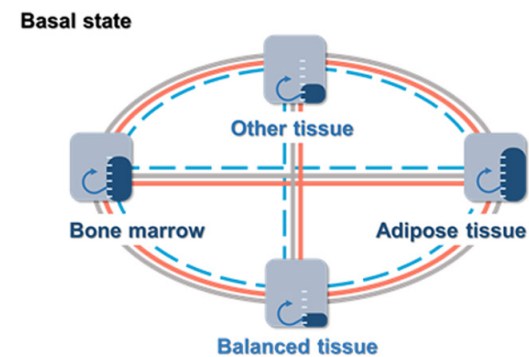

- The stroma represents the connective tissue cells of any organ supporting the functions of the parenchymal compartment and ensuring its homeostasis.

- All tissues virtually contain MSCs pool, however in variable proportions, the adipose tissue (AT) being considered today as the largest reservoir before the bone marrow (BM).

- The different tissues of the organism are connected via the interorgan communication network (ICN) enabling transmission of systemic informations in the form of soluble factors transported by the blood system and chemoelectric via the nervous system.

Questions to be answered:

- Is there a low-grade MSCs mobilization between tissues at the basal state?

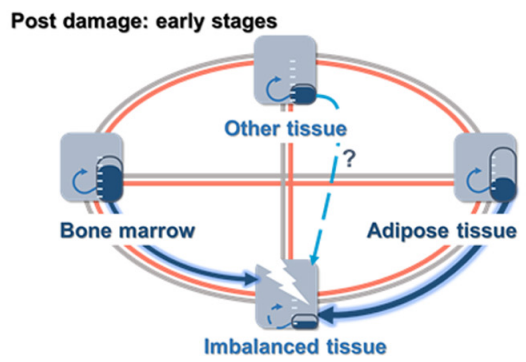

- Following injury, the different cell entities of the stroma contributes to the tissue repair / regeneration.

- Particularly, local MSCs are involved in this process

via their secretory activity and differentiation via their

potentials.
BM and AT are able to liberate MSCs that further infiltrate the distant imbalanced tissue to support its repair / regeneration.

- The stromastat represents the integrated system allowing adequate MSCs pool management and distribution depending on tissue needs.

- MSCs mobilisation between organs represent another branch of the ICN

Questions to be answered:

- DO BM and AT sense the stromal need of the imbalanced tissue via the conventionnal ICN or could it be driven by another support?

- Are all MSCs reservoirs mobilizable?

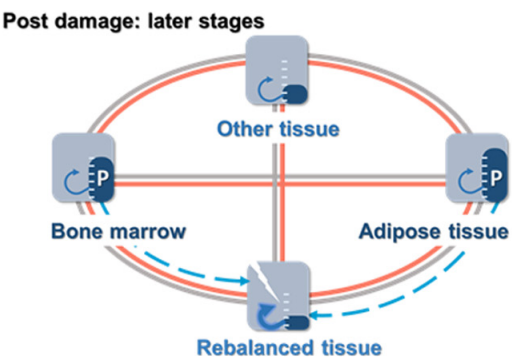

- At later stages following tissue imbalance, the mobilizable MSCs reservoirs replenish their MSCs pool via proliferation processes.

Questions to be answered:

- Do BM and AT replenish their MSCs pool at the same rate? Do they need to " exchange " MSCs to achieve replenishment?

\begin{tabular}{|lll|}
\hline Tissue homeostasis: & $\begin{array}{l}\text { Interorgan } \\
\text { Parenchyme }\end{array}$ & $\begin{array}{l}\text { Communication Network: } \\
\text { Soluble factors }\end{array}$ \\
Stroma & Nervous \\
Proliferation & P & $\begin{array}{l}\text { MSC endogenous } \\
\text { mobilization }\end{array}$ \\
$\begin{array}{l}\text { Tissue } \\
\text { repair/regeneration }\end{array}$ & Hypothetical & $--\cdot$ \\
\hline
\end{tabular}

FIGURE 2 | The stromastat hypothesis within the interorgan communication network during basal and after tissue damage.

functions (Théry et al., 2009; Thomou et al., 2017; Margolis and Sadovsky, 2019). Consequently, the ICN encompasses other modes of communication than secreted molecules, and as such, whether the circulation of MSCs is a way of communication between organs needs to be considered.

\section{Circulating Mesenchymal Stem/Stromal Cells, a Way to Communicate Between Bodily Stromas}

As stated above, the stromal compartment of each organ structures, nurtures, and remodels the functional compartment to ensure organ homeostasis. MSCs, being a central cellular component of bodily stromas, can be viewed as stroma "sentinel," sensing stromal state and ultimately the organ state. The following scenario regarding the role of circulating endogenous MSCs may be proposed.

Just as suggested for the regulation of body temperature or AT mass in the form of thermostat and adipostat, respectively, bodily stromas could be regulated by a set point to ensure the organism's homeostasis that we will name here the "stromastat." Organ failure leading to stromastat modification could be detected by resident MSCs and trigger the early and rapid transfer from MSC reservoirs to the failing organ. This early transfer of MSCs would support the resident pool of MSCs to allow the rebalance of the failing organ. In parallel, to ensure stromastat, data report that the mobilized reservoir may be replenished (Koning et al., 2013; Figure 2). Thus, a possible answer to the meaning of MSC circulation could be that MSCs may represent the cellular part of the ICN. Indeed, evidence that MSCs may belong to the ICN is accumulating. For instance, following organ imbalance (e.g., inflammation, metabolic stress), we observed that ASCs transfer very early from AT toward inflamed lymph nodes (Gil-Ortega et al., 2013) or injured/remodeling skeletal muscle (Girousse et al., 2019). Similar results were also reported for BM-derived MSCs in response to other inflammatory/injury contexts such as myocardial infarction (Fukuda and Fujita, 2005), cranio cerebral trauma (Deng et al., 2011), and encephalomyelitis (Koning et al., 2013). Interestingly, independently of the clinical context or the reservoir investigated, the common point of those studies is the kinetic with which MSCs transfer from their reservoir to the unbalanced site. Such interorgan MSC transfer involves few amounts of cells when compared to the pool of local MSCs. However, we and others have demonstrated that, though discrete, such infiltration dramatically impacts the fate of the organ repair/regeneration/remodeling (Kumar and Ponnazhagan, 2012; Hu et al., 2013; Koning et al., 2013; Girousse et al., 2019). In addition to this, the impact of this rare MSC population could be amplified by the production of EVs, like an inverted funnel effect.

\section{CONCLUSION AND PERSPECTIVES}

Both the mobilization and circulation of endogenous MSCs in physiology and pathology are undoubtful as seen in the present review. However, there are still several questions to be resolved before understanding the meaning of such circulation. One can argue that this is merely explainable because of current available technologies and lack of MSC-specific markers. Indeed, being a population of rare cells in the blood, we have only scratched the surface of the potential of circulating MSCs in 
diagnostics and regenerative medicine. It appears that in case of "emergency," MSCs traffic from adipose or BM reservoir toward distant "injured/inflamed/imbalanced" organs where infiltrated MSCs trigger local mechanisms to allow repair/regeneration. In return, the MSC provider replenishes its own reservoir so that both compartments balance their respective MSC pools, suggesting the presence of a set point that we suggested to name the "stromastat" (Figure 2). How the stromastat regulates organ responses to various stresses and pathological contexts is completely unexplored. This interorgan way of communication may be an unsuspected source of therapeutic targets to help in maintaining whole-organism homeostasis. At last, a better understanding of the control of endogenous MSC circulation, including the description of mobilization and attraction mechanisms, will represent an essential step that will condition their therapeutic potential.

\section{REFERENCES}

Alm, J. J., Koivu, H., Heino, T. J., Hentunen, T. A., Laitinen, S., and Aro, H. T. (2010). Circulating plastic adherent mesenchymal stem cells in aged hip fracture patients. J. Orthop. Res. 28, 1634-1642.doi: 10.1002/jor.21167

Andreas, K., Sittinger, M., and Ringe, J. (2014). Toward in situ tissue engineering: chemokine-guided stem cell recruitment. Trends Biotechnol. 32, 483-492. doi: 10.1016/j.tibtech.2014.06.008

Ankrum, J. A., Ong, J. F., and Karp, J. M. (2014). Mesenchymal stem cells: immune evasive, not immune privileged. Nat. Biotechnol. 32, 252-260.doi: 10.1038/nbt. 2816

Baer, P. C., and Geiger, H. (2012). Adipose-derived mesenchymal stromal/stem cells: tissue localization, characterization, and heterogeneity. Stem Cells Int. 2012:812693. doi: 10.1155/2012/812693

Bara, J. J., Richards, R. G., Alini, M., and Stoddart, M. J. (2014). Concise review: bone marrow-derived mesenchymal stem cells change phenotype following in vitro culture: implications for basic research and the clinic. Stem Cells 32, 1713-1723.doi: 10.1002/stem.1649

Baryawno, N., Przybylski, D., Kowalczyk, M. S., Kfoury, Y., Severe, N., Gustafsson, K., et al. (2019). A cellular taxonomy of the bone marrow stroma in homeostasis and Leukemia. Cell 177, 1915-1932.e16. doi: 10.1016/j.cell.2019.04.040

Bian, Z.-Y., Li, G., Gan, Y.-K., Hao, Y.-Q., Xu, W.-T., and Tang, T.-T. (2009). Increased number of mesenchymal stem cell-like cells in peripheral blood of patients with bone sarcomas. Arch. Med. Res. 40, 163-168.doi: 10.1016/j. arcmed.2009.01.002

Burl, R. B., Ramseyer, V. D., Rondini, E. A., Pique-Regi, R., Lee, Y.-H., and Granneman, J. G. (2018). Deconstructing adipogenesis induced by $\beta 3$ adrenergic receptor activation with single-cell expression profiling. Cell Metab. 28, 300-309.e4. doi: 10.1016/j.cmet.2018.05.025

Chen, Y., Xiang, L.-X. X., Shao, J.-Z. Z., Pan, R.-L. L., Wang, Y.-X. X., Dong, X.J. J., et al. (2010). Recruitment of endogenous bone marrow mesenchymal stem cells towards injured liver. J. Cell. Mol. Med. 14, 1494-1508.doi: 10.1111/j.15824934.2009.00912.x

Cheng, Y., Samia, A. C., Meyers, J. D., Panagopoulos, I., Fei, B., and Burda, C. (2008). Highly efficient drug delivery with gold nanoparticle vectors for in vivo photodynamic therapy of cancer. J. Am. Chem. Soc. 130, 10643-10647.doi: $10.1021 /$ ja801631c

Churchman, S. M., Jones, E. A., Roshdy, T., Cox, G., Boxall, S. A., McGonagle, D., et al. (2020). Transient existence of circulating mesenchymal stem cells in the deep veins in humans following long bone intramedullary reaming. J. Clin. Med. 9:968.doi: 10.3390/jcm9040968

Crisan, M., Chen, C. W., Corselli, M., Andriolo, G., Lazzari, L., and Peault, B. (2009). Perivascular multipotent progenitor cells in human organs. Ann. N. Y. Acad. Sci. 1176, 118-123.doi: 10.1111/j.1749-6632.2009.04967.x

da Silva Meirelles, L., Chagastelles, P. C., and Nardi, N. B. (2006). Mesenchymal stem cells reside in virtually all post-natal organs and tissues. J. Cell Sci. 119, 2204-2213.doi: 10.1242/jcs.02932

\section{AUTHOR CONTRIBUTIONS}

All authors contributed to the design and writing of the manuscript. AG, MM, QS-A, SM, and LC proofread and given comments as well as suggestions. AG designed all the figures. CS supervised and finalized the manuscript.

\section{FUNDING}

Funding supported from the INSERM: French National Reasearch Health Institute, CNRS: French National Research Institute, the University of Toulouse, the FRM (ING20140129326): Fondation pour la recherche médicale, the AFM-TELETHON (23384): Association Française pour la Myopathie, Téléthon.

Deng, J., Zou, Z., Zhou, T., Su, Y., Ai, G., Wang, J., et al. (2011). Bone marrow mesenchymal stem cells can be mobilized into peripheral blood by G-CSF in vivo and integrate into traumatically injured cerebral tissue. Neurol. Sci. 32, 641-651.doi: 10.1007/s10072-011-0608-2

Dixon, J. B., Greiner, S. T., Gashev, A. A., Cote, G. L., Moore, J. E., and Zawieja, D. C. (2006). Lymph flow, shear stress, and lymphocyte velocity in rat mesenteric prenodal lymphatics. Microcirculation 13, 597-610. doi: 10.1080/ 10739680600893909

Dominici, M., Le Blanc, K., Mueller, I., Slaper-Cortenbach, I., Marini, F., Krause, D., et al. (2006). Minimal criteria for defining multipotent mesenchymal stromal cells. The international society for cellular therapy position statement. Cytotherapy 8, 315-317.doi: 10.1080/14653240600855905

Droujinine, I., and Perrimon, N. (2013). Defining the interorgan communication network: systemic coordination of organismal cellular processes under homeostasis and localized stress. Front. Cell. Infect. Microbiol. 3:82. doi: 10. 3389/fcimb.2013.00082

Droujinine, I. A., and Perrimon, N. (2016). Interorgan communication pathways in physiology: focus on Drosophila. Annu. Rev. Genet. 50, 539-570.doi: 10.1146/ annurev-genet-121415-122024

Eisinger, F., Patzelt, J., and Langer, H. F. (2018). The platelet response to tissue injury. Front. Med. 5:317. doi: 10.3389/fmed.2018.00317

Feeback, D. L. (1987). "Organs and systems," in Histology Oklahoma Notes, ed. D. L. Feeback (New York, NY: Springer), 89-190. doi: 10.1007/978-1-4612-4630-5_3

Fellous, T. G., Redpath, A. N., Fleischer, M. M., Gandhi, S., Hartner, S. E., Newton, M. D., et al. (2020). Pharmacological tools to mobilise mesenchymal stromal cells into the blood promote bone formation after surgery. NPJ Regen. Med. 5:3. doi: 10.1038/s41536-020-0088- 1

Fernandez, M., Simon, V., Herrera, G., Cao, C., Del Favero, H., and Minguell, J. J. (1997). Detection of stromal cells in peripheral blood progenitor cell collections from breast cancer patients. Bone Marrow Transplant. 20, 265-271.doi: 10.1038/ sj.bmt. 1700890

Follain, G., Herrmann, D., Harlepp, S., Hyenne, V., Osmani, N., Warren, S. C., et al. (2020). Fluids and their mechanics in tumour transit: shaping metastasis. Nat. Rev. Cancer 20, 107-124. doi: 10.1038/s41568-0190221-x

Fraser, J. K., Zhu, M., Wulur, I., and Alfonso, Z. (2008). Adipose-derived stem cells. Methods Mol. Biol. 449, 59-67. doi: 10.1007/978-1-60327-169-1_4

Friedenstein, A. J., Chailakhjan, R. K., and Lalykina, K. S. (1970). The development of fibroblast colonies in monolayer cultures of guinea-pig bone marrow and spleen cells. Cell Tissue Kinet. 3, 393-403. doi: 10.1111/j.1365-2184.1970. tb00347.x

Friedenstein, A. J., Petrakova, K. V., Kurolesova, A. I., and Frolova, G. P. (1968). Heterotopic of bone marrow. Analysis of precursor cells for osteogenic and hematopoietic tissues. Transplantation 6, 230-247.

Fukuda, K., and Fujita, J. U. N. (2005). Mesenchymal, but not hematopoietic, stem cells can be mobilized and differentiate into cardiomyocytes after myocardial 
infarction in mice. Kidney Int. 68, 1940-1943.doi: 10.1111/j.1523-1755.2005. 00624.x

Galipeau, J., and Sensébé, L. (2018). Mesenchymal stromal cells: clinical challenges and therapeutic opportunities. Cell Stem Cell 22, 824-833.doi: 10.1016/j.stem. 2018.05.004

Gil-Ortega, M., Fernández-Alfonso, M. S., Somoza, B., Casteilla, L., and Sengenès, C. (2014). Ex vivo microperfusion system of the adipose organ: a new approach to studying the mobilization of adipose cell populations. Int. J. Obes. (Lond.) 38, 1255-1262.doi: 10.1038/ijo.2013.243

Gil-Ortega, M., Garidou, L., Barreau, C., Maumus, M., Breasson, L., Tavernier, G., et al. (2013). Native adipose stromal cells egress from adipose tissue in vivo: evidence during lymph node activation. Stem Cells 31, 1309-1320.doi: 10.1002/ stem. 1375

Gimble, J. M., and Guilak, F. (2003). Differentiation potential of adipose derived adult stem (ADAS) cells. Curr. Top. Dev. Biol. 58, 137-160. doi: 10.1016/s00702153(03)58005-x

Girousse, A., Gil-Ortega, M., Bourlier, V., Bergeaud, C., Sastourné-Arrey, Q., Moro, C., et al. (2019). The release of adipose stromal cells from subcutaneous adipose tissue regulates ectopic intramuscular adipocyte deposition. Cell Rep. 27, 323-333.e5. doi: 10.1016/j.celrep.2019.03.038

Golebiewska, E. M., and Poole, A. W. (2015). Platelet secretion: from haemostasis to wound healing and beyond. Blood Rev. 29, 153-162.doi: 10.1016/j.blre.2014. 10.003

Gould, S. J., Booth, A. M., and Hildreth, J. E. K. (2003). The Trojan exosome hypothesis. Proc. Natl. Acad. Sci. U.S.A. 100, 10592-10597.doi: 10.1073/pnas. 1831413100

Han, M., Watts, J. A., Jamshidi-Parsian, A., Nadeem, U., Siegel, E. R., Zharov, V. P., et al. (2020). Lymph liquid biopsy for detection of cancer stem cells. Cytometry Part A doi: 10.1002/cyto.a.24221. [Epub ahead of print].

He, Q., Wan, C., and Li, G. (2007). Concise review: multipotent mesenchymal stromal cells in blood. Stem Cells 25, 69-77.doi: 10.1634/stemcells.2006-0335

Heeke, S., Mograbi, B., Alix-Panabières, C., and Hofman, P. (2019). Never travel alone: the crosstalk of circulating tumor cells and the blood microenvironment. Cells 8:714.doi: 10.3390/cells8070714

Hénon, P. (2020). Key success factors for regenerative medicine in acquired heart diseases. Stem Cell Rev. Rep. 16, 441-458.doi: 10.1007/s12015-020-09961-0

Hepler, C., Shan, B., Zhang, Q., Henry, G. H., Shao, M., Vishvanath, L., et al. (2018). Identification of functionally distinct fibro-inflammatory and adipogenic stromal subpopulations in visceral adipose tissue of adult mice. Elife 7:e39636. doi: 10.7554/eLife.39636

Hoogduijn, M. J., Verstegen, M. M. A., Engela, A. U., Korevaar, S. S., Roemelingvan Rhijn, M., Merino, A., et al. (2014). No evidence for circulating mesenchymal stem cells in patients with organ injury. Stem Cells Dev. 23, 2328-2335.doi: 10.1089/scd.2014.0269

Hou, D., Youssef, E. A.-S., Brinton, T. J., Zhang, P., Rogers, P., Price, E. T., et al. (2005). Radiolabeled cell distribution after intramyocardial, intracoronary, and interstitial retrograde coronary venous delivery: implications for current clinical trials. Circulation 112, I150-I156. doi: 10.1161/CIRCULATIONAHA. 104.526749

Hu, C., Yong, X., Li, C., Lü, M., Liu, D., Chen, L., et al. (2013). CXCL12/CXCR4 axis promotes mesenchymal stem cell mobilization to burn wounds and contributes to wound repair. J. Surg. Res. 183, 427-434.doi: 10.1016/j.jss.2013.01.019

Huet, E., Jaroz, C., Nguyen, H. Q., Belkacemi, Y., de la Taille, A., Stavrinides, V., et al. (2019). Stroma in normal and cancer wound healing. FEBS J. 286, 2909-2920.doi: 10.1111/febs. 14842

Jones, E., and Schäfer, R. (2015). Biological differences between native and cultured mesenchymal stem cells: implications for therapies. Methods Mol. Biol. 1235, 105-120.doi: 10.1007/978-1-4939-1785-3_10

Jones, E. A., English, A., Kinsey, S. E., Straszynski, L., Emery, P., Ponchel, F., et al. (2006). Optimization of a flow cytometry-based protocol for detection and phenotypic characterization of multipotent mesenchymal stromal cells from human bone marrow. Cytometry B Clin. Cytom. 70, 391-399.doi: 10.1002/cyto. b. 20118

Keating, A. (2012). Mesenchymal stromal cells: new directions. Cell Stem Cell 10, 709-716.doi: 10.1016/j.stem.2012.05.015

Koh, Y. J., Kang, S., Lee, H. J., Choi, T. S., Lee, H. S., Cho, C. H., et al. (2007). Bone marrow-derived circulating progenitor cells fail to transdifferentiate into adipocytes in adult adipose tissues in mice. J. Clin. Invest. 117, 3684-3695. doi: $10.1172 /$ jci32504

Kolonin, M. G. (2012). Progenitor cell mobilization from extramedullary organs. Methods Mol. Biol. 904, 243-252.doi: 10.1007/978-1-61779-943-3_20

Koning, J. J., Kooij, G., de Vries, H. E., Nolte, M. A., and Mebius, R. E. (2013). Mesenchymal stem cells are mobilized from the bone marrow during inflammation. Front. Immunol. 4:49. doi: 10.3389/fimmu.2013.00049

Krankel, N., Spinetti, G., Amadesi, S., and Madeddu, P. (2011). Targeting stem cell niches and trafficking for cardiovascular therapy. Pharmacol. Ther. 129, 62-81.doi: 10.1016/j.pharmthera.2010.10.002

Kumar, S., and Ponnazhagan, S. (2012). Mobilization of bone marrow mesenchymal stem cells in vivo augments bone healing in a mouse model of segmental bone defect. Bone 50, 1012-1018.doi: 10.1016/j.bone.2012.01.027

Langer, H. F., Stellos, K., Steingen, C., Froihofer, A., Schönberger, T., Krämer, B., et al. (2009). Platelet derived bFGF mediates vascular integrative mechanisms of mesenchymal stem cells in vitro. J. Mol. Cell. Cardiol. 47, 315-325.doi: 10.1016/j.yjmcc.2009.03.011

Lazarus, H. M., Haynesworth, S. E., Gerson, S. L., and Caplan, A. I. (1997). Human bone marrow-derived mesenchymal (stromal) progenitor cells (MPCs) cannot be recovered from peripheral blood progenitor cell collections. J. Hematother. 6, 447-455.doi: 10.1089/scd.1.1997.6.447

Li, X., Ling, W., Khan, S., and Yaccoby, S. (2012). Therapeutic effects of intrabone and systemic mesenchymal stem cell cytotherapy on myeloma bone disease and tumor growth. J. Bone Miner. Res. 27, 1635-1648.doi: 10.1002/jbmr.1620

Lindskog, C. (2015). The potential clinical impact of the tissue-based map of the human proteome. Expert Rev. Proteomics 12, 213-215. doi: 10.1586/14789450. 2015.1040771

Liu, Y., Yang, X., Jing, Y., Zhang, S., Zong, C., Jiang, J., et al. (2015). Contribution and mobilization of mesenchymal stem cells in a mouse model of carbon tetrachloride-induced liver fibrosis. Sci. Rep. 5:17762. doi: 10.1038/srep17762

Mansilla, E., Marin, G. H., Drago, H., Sturla, F., Salas, E., Gardiner, C., et al. (2006). Bloodstream cells phenotypically identical to human mesenchymal bone marrow stem cells circulate in large amounts under the influence of acute large skin damage: new evidence for their use in regenerative medicine. Transplant. Proc. 38, 967-969. doi: 10.1016/j.transproceed.2006.02.053

Margolis, L., and Sadovsky, Y. (2019). The biology of extracellular vesicles: the known unknowns. PLoS Biol. 17:e3000363. doi: 10.1371/journal.pbio.3000363

Marketou, M. E., Parthenakis, F. I., Kalyva, A., Pontikoglou, C., Maragkoudakis, S., Kontaraki, J. E., et al. (2014). Increased mobilization of mesenchymal stem cells in patients with essential hypertension: the effect of left ventricular hypertrophy. J. Clin. Hypertens. (Greenwich) 16, 883-888. doi: 10.1111/jch.12426

Marketou, M. E., Parthenakis, F. I., Kalyva, A., Pontikoglou, C., Maragkoudakis, S., Kontaraki, J. E., et al. (2015). Circulating mesenchymal stem cells in patients with hypertrophic cardiomyopathy. Cardiovasc. Pathol. 24, 149-153. doi: 10. 1016/j.carpath.2015.02.005

Massberg, S., Schaerli, P., Knezevic-Maramica, I., Köllnberger, M., Tubo, N., Ashley Moseman, E., et al. (2007). Physiological recirculation of hematopoietic stem and progenitor cells through blood, lymph and extramedullary tissues. Cell 131, 994-1008. doi: 10.1016/j.cell.2007.09.047

Maumus, M., Peyrafitte, J.-A., D’Angelo, R., Fournier-Wirth, C., Bouloumié, A., Casteilla, L., et al. (2011). Native human adipose stromal cells: localization, morphology and phenotype. Int. J. Obes. (Lond.) 35, 1141-1153. doi: 10.1038/ ijo.2010.269

Maximow, A. A. (1928). Cultures of blood leucocytes; from lymphocyte and monocyte to connective tissue. Arch. Exp. Zellforsch. 5, 169-268.

Nieswandt, B., Hafner, M., Echtenacher, B., and Männel, D. N. (1999). Lysis of tumor cells by natural killer cells in mice is impeded by platelets. Cancer Res. 59, 1295-1300.

Ode, A., Kopf, J., Kurtz, A., Schmidt-Bleek, K., Schrade, P., Kolar, P., et al. (2011). CD73 and CD29 concurrently mediate the mechanically induced decrease of migratory capacity of mesenchymal stromal cells. Eur. Cells Mater. 22, 26-42.

Ojeda-Uribe, M., Brunot, A., Lenat, A., and Legros, M. (1993). Failure to detect spindle-shaped fibroblastoid cell progenitors in PBPC collections. Acta Haematol. 90, 139-143. doi: 10.1159/000204395

Parekkadan, B., and Milwid, J. M. C. (2010). Mesenchymal stem cells as therapeutics. Ann. Rev. Biomed. Eng. 12, 87-117. doi: 10.1146/annurev-bioeng070909-105309 
Pittenger, M. F., Discher, D. E., Péault, B. M., Phinney, D. G., Hare, J. M., and Caplan, A. I. (2019). Mesenchymal stem cell perspective: cell biology to clinical progress. NPJ Regen. Med. 4:22. doi: 10.1038/s41536-019-0083-6

Platt, A. M., and Randolph, G. J. (2013). "Cellular composition of lymph," in Immunology of the Lymphatic System, ed. L. Santambrogio (New York, NY: Springer), 53-64. doi: 10.1007/978-1-4614-3235-7_4

Qian, H., Le Blanc, K., and Sigvardsson, M. (2012). Primary mesenchymal stem and progenitor cells from bone marrow lack expression of CD44 protein. J. Biol. Chem. 287, 25795-25807. doi: 10.1074/jbc.M112.339622

Rebolj, K., Veber, M., Drobniè, M., and Malièev, E. (2018). Hematopoietic stem cell and mesenchymal stem cell population size in bone marrow samples depends on patient's age and harvesting technique. Cytotechnology 70, 1575-1583. doi: 10.1007/s10616-018-0250-4

Rege, T. A., and Hagood, J. S. (2006). Thy-1 as a regulator of cell-cell and cell-matrix interactions in axon regeneration, apoptosis, adhesion, migration, cancer, and fibrosis. FASEB J. 20, 1045-1054. doi: 10.1096/fj.05-5460rev

Roufosse, C. A., Direkze, N. C., Otto, W. R., and Wright, N. A. (2004). Circulating mesenchymal stem cells. Int. J. Biochem. Cell Biol. 36, 585-597. doi: 10.1016/j. biocel.2003.10.007

Santambrogio, L. (2018). "Chapter four - the lymphatic fluid," in International Review of Cell and Molecular Biology, ed. L. Galluzzi (Cambridge, MA: Academic Press), 111-133. doi: 10.1016/bs.ircmb.2017.12.002

Scadden, D. T. (2012). Rethinking stroma: lessons from the blood. Cell Stem Cell 10, 648-649. doi: 10.1016/j.stem.2012.05.011

Schreier, S., and Triampo, W. (2020). The blood circulating rare cell population. What is it and what is it good for? Cells 9:790. doi: 10.3390/cells9040790

Schwarz, S., Huss, R., Schulz-Siegmund, M., Vogel, B., Brandau, S., Lang, S., et al. (2014). Bone marrow-derived mesenchymal stem cells migrate to healthy and damaged salivary glands following stem cell infusion. Int. J. Oral Sci. 6, 154-161. doi: 10.1038/ijos.2014.23

Sengenès, C., Lolmède, K., Zakaroff-Girard, A., Busse, R., and Bouloumié, A. (2005). Preadipocytes in the human subcutaneous adipose tissue display distinct features from the adult mesenchymal and hematopoietic stem cells. J. Cell. Physiol. 205, 114-122. doi: 10.1002/jcp.20381

Sheriff, L., Alanazi, A., Ward, L. S. C., Ward, C., Munir, H., Rayes, J., et al. (2018). Origin-specific adhesive interactions of mesenchymal stem cells with platelets influence their behavior after infusion. Stem Cells 36, 1062-1074. doi: 10.1002/ stem. 2811

Silverthon, D., Ober, W., Garrison, C., Silverthon, A., and Johnson, B. (2009). Human Physiology: An Integrated Approach, 7th Edn. San Francisco, CA: Pearson/Benjamin Cummings.

Teo, G. S. L., Yang, Z., Carman, C. V., Karp, J. M., and Lin, C. P. (2015). Intravital imaging of mesenchymal stem cell trafficking and association with platelets and neutrophils. Stem Cells 33, 265-277. doi: 10.1002/stem.1848

Tesfamariam, B. (2016). Involvement of platelets in tumor cell metastasis. Pharmacol. Ther. 157, 112-119. doi: 10.1016/j.pharmthera.2015.11.005

Théry, C., Ostrowski, M., and Segura, E. (2009). Membrane vesicles as conveyors of immune responses. Nat. Rev. Immunol. 9, 581-593. doi: 10.1038/nri2567

Thomou, T., Mori, M. A., Dreyfuss, J. M., Konishi, M., Sakaguchi, M., Wolfrum, C., et al. (2017). Adipose-derived circulating miRNAs regulate gene expression in other tissues. Nature 542, 450-455. doi: 10.1038/nature21365

Uhlen, M., Oksvold, P., Fagerberg, L., Lundberg, E., Jonasson, K., Forsberg, M., et al. (2010). Towards a knowledge-based human protein Atlas. Nat. Biotechnol. 28, 1248-1250. doi: 10.1038/nbt1210-1248
Valkenburg, K. C., de Groot, A. E., and Pienta, K. J. (2018). Targeting the tumour stroma to improve cancer therapy. Nat. Rev. Clin. Oncol. 15, 366-381. doi: 10.1038/s41571-018-0007-1

Walter, S. G., Randau, T. M., Hilgers, C., Haddouti, E.-M., Masson, W., Gravius, S., et al. (2020). Molecular and functional phenotypes of human bone marrowderived mesenchymal stromal cells depend on harvesting techniques. Int. J. Mol. Sci. 21:4382. doi: 10.3390/ijms21124382

Wang, Y., Johnsen, H. E., Mortensen, S., Bindslev, L., Ripa, R. S., HaackSorensen, M., et al. (2006). Changes in circulating mesenchymal stem cells, stem cell homing factor, and vascular growth factors in patients with acute ST elevation myocardial infarction treated with primary percutaneous coronary intervention. Heart 92, 768-774. doi: 10.1136/hrt.2005.069799

Ward, L. S. C., Sheriff, L., Marshall, J. L., Manning, J. E., Brill, A., Nash, G. B., et al. (2019). Podoplanin regulates the migration of mesenchymal stromal cells and their interaction with platelets. J. Cell. Sci. 132:jcs222067. doi: 10.1242/jcs. 222067

Wexler, S. A., Donaldson, C., Denning-Kendall, P., Rice, C., Bradley, B., and Hows, J. M. (2003). Adult bone marrow is a rich source of human mesenchymal "stem" cells but umbilical cord and mobilized adult blood are not. Br. J. Haematol. 121, 368-374. doi: 10.1046/j.1365-2141.2003.04284.x

Wojakowski, W., Kucia, M., KaÅomierski, M., Ratajczak, M. Z., and Tendera, M. (2008). Circulating progenitor cells in stable coronary heart disease and acute coronary syndromes: relevant reparatory mechanism? Heart 94, 27-33. doi: 10.1136/hrt.2006.103358

Wolock, S. L., Krishnan, I., Tenen, D. E., Matkins, V., Camacho, V., Patel, S., et al. (2019). Mapping distinct bone marrow niche populations and their differentiation paths. Cell Rep. 28, 302-311.e5. doi: 10.1016/j.celrep.2019.06. 031

Wong, S. Y., and Hynes, R. O. (2006). Lymphatic or hematogenous dissemination: how does a metastatic tumor cell decide? Cell Cycle 5, 812-817.

$\mathrm{Xu}, \mathrm{L}$. , and Li, G. (2014). Circulating mesenchymal stem cells and their clinical implications. J. Orthop. Translat. 2, 1-7. doi: 10.1016/j.jot.2013.11.002

Zhang, Y., Daquinag, A., Traktuev, D. O., Amaya-Manzanares, F., Simmons, P. J., March, K. L., et al. (2009). White adipose tissue cells are recruited by experimental tumors and promote cancer progression in mouse models. Cancer Res. 69, 5259-5266.

Zuk, P. A., Zhu, M., Mizuno, H., Huang, J., Futrell, J. W., Katz, A. J., et al. (2001). Multilineage cells from human adipose tissue: implications for cell-based therapies. Tissue Eng. 7, 211-228.

Zvaifler, N. J., Marinova-Mutafchieva, L., Adams, G., Edwards, C. J., Moss, J., Burger, J. A., et al. (2000). Mesenchymal precursor cells in the blood of normal individuals. Arthritis Res. 2, 477-488. doi: 10.1186/ar130

Conflict of Interest: The authors declare that the research was conducted in the absence of any commercial or financial relationships that could be construed as a potential conflict of interest.

Copyright (c) 2021 Girousse, Mathieu, Sastourné-Arrey, Monferran, Casteilla and Sengenès. This is an open-access article distributed under the terms of the Creative Commons Attribution License (CC BY). The use, distribution or reproduction in other forums is permitted, provided the original author(s) and the copyright owner(s) are credited and that the original publication in this journal is cited, in accordance with accepted academic practice. No use, distribution or reproduction is permitted which does not comply with these terms. 